\title{
A influência da alimentação como agente precursor, preventivo e redutor do câncer
}

\author{
Viviane Alves Figueredo ${ }^{1}$ \\ Cláudio Henrique Cerri e Silva ${ }^{2}$
}

\begin{abstract}
RESUMO - O câncer é uma doença que se manifesta através de mais de 100 formas, proporcionadas por sucessivas mitoses que ocasionam tumores benignos e malignos. O número de casos vem crescendo devido aos vários fatores que desencadeiam as neoplasias, dos quais vem se destacando os maus hábitos alimentares. Uma dieta desequilibrada com alto consumo de gorduras saturadas e hidrogenadas, ou ainda algumas substâncias embutidas nos alimentos podem vir a ocasionar a gênese carcinogênica. Por outro lado, uma dieta que enfatize maior ingestão de fibras, antioxidantes, carotenóides, vitaminas, proteínas e ainda rica em ácidos graxos ômega 3, propicia o auto controle fisiológico do organismo, além de aumentar a proliferação imunológica do mesmo. Portanto, o consumo de alimentos com teor nutricional desequilibrado deve ser evitado ou realizada com pouca frequiência, buscando, corriqueiramente, adicionar à dieta maior quantidade de frutas e vegetais, bem como variar a dieta para que haja equilíbrio do organismo.
\end{abstract}

Palavras-chave: alimentação, prevenção, câncer.

\section{Food influence like a proceeding and reduction of cancer}

\begin{abstract}
The cancer is a disease that shows through more than 100 forms, proportionate for successive mitoses that cause benign and evil tumors. The number of cases is growing due to the several factors that unchain the neoplasias, which it is highlighting the bad alimentary habits. An unbalanced diet with high consumption of saturated fats and hydrogenated, or still some substances embedded in the food can come to cause the carcinogenesis. On the other hand, a diet that emphasizes
\end{abstract}

Monografia de conclusão do curso de Ciências com Habilitação em Biologia, apresentada ao UniCEUB no primeiro semestre de 2001 .

${ }^{1}$ Graduada no curso de Ciências Biológicas do UniCEUB.

${ }^{2}$ Professor da Faculdade de Ciências da Saúde do Centro Universitário de Brasília - UniCEUB (e-mail: claudio.cerri@uniceub.br). 
larger ingestion of fibers, antioxidants, carotene, vitamins, proteins and still rich in fatty acids omega 3 , it propitiates the physiologic self controls of the organism, besides increasing the immunology response of the same. Therefore, the consumption of victuals with tenor unbalanced nutritional should be avoided or accomplished with little frequency, looking for, frequently, to add to the diet larger

amount of fruits and vegetables, as well as to vary the diet so that there is balance of the organism.

Key words: feeding, prevention, cancer.

Câncer é um grupo de doenças caracterizadas por proliferação celular desordenada que, por meio de metástase, pode invadir tecidos e órgãos vizinhos ou à distância, podendo levar o indivíduo à morte (Junqueira \& Carneiro, 1999; Mori, 2002).

Dividindo-se rapidamente, as células neoplásicas tendem a ser muito agressivas e incontroláveis, podendo levar ao acúmulo de células cancerosas também conhecidas como neoplasias malignas. Por outro lado, um tumor benigno significa simplesmente uma massa localizada de células que se multiplicam vagarosamente e se assemelha ao seu tecido original, raramente constituindo um risco de vida (Instituto Nacional do Câncer - INCA, 2001; Sgarbieri, 1999).

\section{Principais agentes carcinogênicos}

Existem vários fatores que causam o câncer e estão classificados em externos, ligados ao meio ambiente e aos hábitos e costumes socioculturais, e os internos, geneticamente pré-determinados e ligados à capacidade do organismo de se defender das agressões externas. A interação desses fatores aumenta a probabilidade de gerar neoplasias malignas em células normais (Lewin, 2001).

Dentre os principais fatores externos que estão associados a neoplasias malignas, encontram-se os fatores biológicos, como as infecções causadas por vírus e bactérias que podem levar a alterações genéticas em pessoas que não herdaram genes mutados, o uso prolongado e diário de agrotóxicos em cereais, frutas e legumes nas lavouras, alcoolismo e tabagismo. Em indivíduos que bebem e/ou fumam diariamente ocorre aumento em até $60 \%$ das chances de desenvolvimento de câncer quando associados a alimentação rica em gorduras, frituras ou alimentos industrializados ricos em corantes e conservantes (Núcleo de Apoio ao Paciente com Câncer - NAPACAN, 2001). 


\section{Dieta como fator de risco para o câncer}

Estudos evidenciam a relação entre componentes específicos da alimentação e desenvolvimento de certos tipos de câncer, especialmente os que têm origem no sistema endócrino (mama e próstata) ou digestório (cólon e estômago). Arnot (1998), propõe que cerca de 35\% dos óbitos provocados por câncer nos Estados Unidos estão ligados à dieta e estima que $40 \%$ da incidência do câncer nos homens e $60 \%$ nas mulheres estão associados aos hábitos alimentares.

Uma das principais metas da alimentação consiste em manter o organismo em equilíbrio ativo com a natureza, proporcionando maior tempo de vida e melhor qualidade da mesma, especificamente nos aspectos físico e mentais do ser humano.

Algumas substâncias adicionadas aos alimentos, como os corantes e os conservantes, acumulam-se no organismo e deve-se tomar um cuidado maior quanto as suas doses de ingestão diária. Mesmo considerando-se uma parcial eliminação dessas substâncias e uma degradação metabólica da mesma, deve-se destacar que não existem informações bem definidas para cada substância quanto a dose diária de ingestão e o risco da carcinogênese. Dependendo da substância, uma pequena dose ingerida diariamente e por tempo prolongado, pode resultar no câncer (Lederer, 1990).

\section{Substâncias moduladoras do desenvolvimento do câncer}

Algumas substâncias podem se destacar no processo carcinogênico, entre as quais encontram-se as nitrosaminas, substâncias que representam perigo à saúde quando empregadas nos alimentos, pois apresentam alto poder cancerígeno através da sua ligação ao DNA (INCA, 2000). São provenientes dos nitritos e dos nitratos de sódio por meio de um processo denominado nitrosação, que se dá pela atuação do ácido nitroso sobre uma amina secundária em $\mathrm{pH}$ variando de 2 a 3 que predomina no momento da digestão no estômago. Este processo pode vir a se agravar quando este órgão encontra-se debilitado por ação de gastrite em um alto estágio de anormalidade. As nitrosaminas podem ser encontradas em legumes que sejam provenientes de solos ricos em nitrato, em bebidas alcóolicas, nos laticínios, especialmente no leite pasteurizado e em peixes ou carnes conservados com nitrito de soda. A água também pode favorecer ao aparecimento de tumores, se apresentar uma alta concentração de nitrito.

Os alimentos defumados podem representar outro fator de risco, por conterem o benzo-pireno. Estatísticas revelam que os consumidores mais assíduos dos alimentos defumados têm maior incidência de morte prematura por câncer, em 
relação a pessoas que não fazem ingestão freqüente destes alimentos. Segundo Lederer (1990), vários fatores favorecem à concentração do benzo-pireno nos alimentos defumados: o teor de concentração de fumaça que impregna na carne, a quantidade de fuligem depositada nas grelhas, a qualidade do carvão vegetal, a temperatura e o tempo de conservação dos alimentos defumados, uma vez que a concentração de benzo-pireno aumenta com o passar do tempo.

As gorduras são outras substâncias que se destacam no processo carcinogênico. Seu consumo vem crescendo significativamente em vários países, dentre os quais está o Brasil. Este aumento se deve ao fato das gorduras estarem embutidas em produtos de procedência principalmente industrializada.

Existem relações entre a ingestão de alimentos ricos em gorduras, especialmente alimentos de origem animal, e vários tipos de câncer, em específico o câncer de mama, cólon e próstata. Esta associação vem sendo comprovada tanto em estudos epidemiológicos, quanto laboratoriais. Pesquisas têm mostrado evidências de que mesmo após a regulação da ingestão de altas quantidades de gorduras, a quantidade total de lipídios no organismo coincide com o surgimento de câncer em vários órgãos (Sgarbieri, 1999).

O processo pelo qual a dieta calórica proporciona o aparecimento do câncer de cólon está ligado a atividade metabólica da microflora fecal e à concentração dos substratos esteróides localizados no intestino grosso. Grandes concentrações de gordura no bolo fecal proporciona o aumento da liberação de ácidos biliares no intestino. Estes, em alta concentração são citotóxicos e podem agir como promotores de tumores (Sgarbieri, 1999).

Segundo Arnot (1998), verificou-se que o número de ocorrências de câncer de mama em japonesas é cinco vezes menor do que entre as mulheres norteamericanas e européias. Os casos existentes de desenvolvimento tumoral nas asiáticas são intensamente vagarosos. No entanto, ao migrarem para os continentes ocidentais e incorporarem ao seu cotidiano os hábitos alimentares da região, estes índices crescem de forma assustadora e podem chegar aos mesmos índices das mulheres ocidentais. Pequenas alterações na dieta alimentar não trazem maiores risco de gênese ao câncer, no entanto, várias mudanças no padrão alimentar como dietas ricas em gorduras, podem ocasionar significantes danos à saúde, em especial, a saúde da mulher.

As gorduras saturadas possuem grande aptidão de aumentar as taxas de insulina, promovendo uma resposta conhecida como regulação para baixo ("down regulation"), onde o número de receptores a esse hormônio diminuem, através de endocitose, após uma superexposição ao mesmo (Tortora e Grabowski, 2002). Isso diminui a reatividade das células ao hormônio e dificulta o transporte de 
glicose para o músculo, retardando seu processo de absorção. Isso leva a produzir taxas muito mais altas de insulina, o que provocará, também, um aumento da taxa de gordura no sangue, obesidade e risco aumentado de câncer. As fontes mais importantes de gordura saturada são leite e derivados integrais, carnes vermelhas gordurosas e aves com pele (Arnot, 1998).

Os ácidos graxos trans hidrogenados são ácidos graxos ômega 6 e estão presentes em óleos quimicamente hidrogenados que apresentam uma textura cremosa. Em sua maioria são encontrados em alimentos processados, tornandoos mais saborosos e crocantes, além de proporcionar aumento do tempo de conservação dos mesmos. Segundo Arnot (1998) as gorduras hidrogenadas podem atuar sobre as prostaglandinas, substâncias responsáveis pela contração de alguns órgãos de musculatura lisa. As prostaglandinas reduzem o efeito propulsor das células dos ductos lactíferos, favorecendo o surgimento de nódulos no seio. Atualmente o consumo de gorduras ômega 6 é mais elevado em relação às gorduras ômega 3. Esta pode ocasionar a inibição da multiplicação celular de vários órgãos, especificamente as células situadas na mama.

\section{Dieta como agente preventivo e redutor do câncer}

Uma nutrição adequada e apropriada é indispensável para a manutenção da saúde. Contribui tanto para a diminuição de riscos de doenças como também para a restauração da homeostasia em casos de enfermidades. Por meio da alimentação é possível promover a recuperação, reabilitação, desintoxicação e reparo de células, proporcionando maior vitalidade a órgãos e tecidos.

A alimentação pode modificar o processo de carcinogênese, principalmente nos estágios iniciais, proporcionando melhores resultados no tratamento e diagnóstico clínico. Dessa forma, através de um padrão nutricional normal ou equilibrado pode-se reduzir o risco de câncer.

De acordo com a Sociedade Americana de Câncer faz-se necessário seguir alguns padrões ou normas para manter-se mais saudável e prevenir outras moléstias. Entre esses padrões tem-se: praticar exercícios físicos, limitar o consumo de bebidas alcóolicas, preferir alimentos de origem vegetal entre muitos alimentos que se ingere e limitar o consumo de alimentos gordurosos, particularmente de origem animal.

Os ácidos graxos ômega 3 encontrados em maior quantidade em alguns peixes, vem sendo apontado como um alimento preventivo ao câncer mamário. Há uma incidência pequena de câncer de mama em mulheres esquimós da Groelândia, que consomem uma das mais altas concentrações de ácidos graxos 
ômega 3 do mundo. No entanto, em doses elevadas, o ômega 3 pode causar hemorragias. Portanto, deve-se ter maiores cuidados em sua utilização. Milhares de mulheres que se encontravam em um quadro de risco e que já foram portadoras de câncer de mama, consomem os ácidos graxos ômega 3 como suplementação (Cave, 1996).

As fibras também são inibidoras da ação de alguns agentes carcinogênicos provenientes da ação de gorduras (Sgarbieri, 1999). Elas reduzem a ação do estrogênio, diminuindo suas taxas no sangue e proporcionando menor risco de incidência de câncer de mama em mulheres. Também são grandes estimulantes dos movimentos peristálticos do tubo intestinal, mantendo a função normal da área gastrointestinal, bem como removem resíduos alimentares aderidos às dobras das alças do tubo, eliminando matéria em estado de apodrecimento, dentre as quais incluem-se toxinas que podem ocasionar câncer nessa região.

As fibras insolúveis, em especial a celulose, presente em abundância no farelo de trigo, prendem mais eficientemente o estrogênio nos intestinos. Por outro lado as fibras solúveis controlam melhor a fome, a taxa de açúcar no sangue e o colesterol. Geralmente o alimento que contém 1 grama de fibra solúvel, contém 3 gramas de fibras insolúveis. Verifica-se que uma dieta rica em fibras oferece um ótimo controle nas taxas de insulina e de glicose, uma vez que retém os açúcares no estômago, liberando-os lentamente na corrente sangüínea.

As frutas, verduras e legumes são alimentos ricos em fibras e antioxidantes, como por exemplo a vitamina $\mathrm{C}$. As fibras presentes nestes alimentos combatem naturalmente a fome e substituem, de certa forma, a ingestão de gorduras e carboidratos. As vitaminas, poderosos antioxidantes, reduzem a carga dos agentes oxidantes associados ao surgimento de cânceres (La Vecchia, 1998).

A vitamina A auxilia no ciclo de diferenciação celular de epitélios, onde pode ter origem um câncer. Pessoas que têm dieta pobre em vitamina A se tornam mais susceptíveis ao câncer de pulmão, pois a carência dessa vitamina permite a fixação do benzo(a)pireno no DNA do epitélio traqueal, além de exercer influência na replicação de DNA, tornando-o mais intenso devido ao aumento de timidina, nucleosídeo de timina. Já a flavina tem a função de auxiliar no combate às lesões do esôfago, por proporcionar a manutenção e integridade da sua mucosa. A importância da vitamina $\mathrm{C}$ está associada a vários tipos de câncer. Doses diárias administradas em pacientes com câncer proporcionaram um aumento na sobrevida. A ação da vitamina C estimula a síntese de colágeno e os mecanismos imunológicos, bem como, ajuda no bloqueio do processo de nitrosação, inibe a oxidação de hidrocarbonetos policíclicos e previne a iniciação de cânceres cutâneos. A vitamina E também tem o seu papel anticancerígeno. Ela, além de antioxidante, inibe o efeito cancerígeno da aflatoxina, toxina encontrada em alguns alimentos 
contaminados por fungos do gênero Aspergillus, e previne a formação das nitrosaminas (Lederer, 1990).

Os cogumelos possuem grande diversidade genética que representa uma fonte protéica essencial para a saúde humana. Em termos internacionais, os cogumelos comestíveis apresentam um teor de proteínas (em peso seco) elevado, a despeito do seu alto teor de água quando fresco. Algumas espécies como o Pleurotus sajor caju e o Pleurotus flabellatus, apresentam, em média, 7,5\% a mais de proteínas, quando comparados a carne bovina (Rajaratham \& Bano, 1987).

A utilização dos fungos com propriedades terapêuticas deve-se ao alívio ou cura de enfermidades como pressão alta e cardiopatias, entre as quais o câncer (Hayes \& Wright, 1979).

Atribui-se aos cogumelos propriedade antivirais, antibióticos, antiinflamatórios, hipoglicêmicos, anti-hipertensivos e antitumoral. Estas atividades podem ser ferramentas promissoras contra as neoplasias, quando em associação com os tratamentos convencionais, pois atuam no aumento da resposta imunológica do organismo debilitado (Gennari, Gennari \& Felippe, 2001).

Substâncias como o polissacarídeo lentinana, uma b-1,3-glucana isolada de Lentinula (Lentinus) edodes, com atividade antitumoral, tem sido testados em ratos e mostrado a resposta imune dos linfócitos T. Outra substância, a eritadenina (ácido 2(R), 3(R)-dihidróxi-4-(9 adenil) butírico) apresenta atividade anticolesterol. Além dos polissacarídeos, os Lentinus edodes dão origem a outras substâncias com atividade anticarcinogênica. Exemplos de cogumelos com atividade antitumoral, além do L. edodes, estão os Pleurotus sp. Flamullina velutipes, Agaricus bisporus, Agaricus blazei e os Hericium erinaceus (Hayes \& Wright, 1979).

O motivo evidente de várias espécies de fungos serem utilizados como substâncias preventivas e até redutoras de tumores, está associado ao polissacarídeo presente em sua parede celular que pode estimular a formação de anticorpos. Os anticorpos não atuam como agentes que podem matar diretamente as células cancerígenas, no entanto, atuam como poderosos agentes secundários onde, associados à outras substâncias de procedência inorgânicas, ou seja, em combinação com quimioterápicos, podem reverter o estágio tumoral. Atualmente, se conhece cerca de 220 espécies de fungos que apresentam valor terapêutico e muitos têm tido seu uso intensificado (Hayes \& Wright, 1979). 


\section{Conclusões}

Em meio aos vários fatores que dão origem à carcinogênese, a dieta vem se destacando, seja como precursora, seja como retardadora ou inibidora da moléstia.

O desequilíbrio alimentar pode trazer a médio ou longo prazo transtornos e patologias preocupantes ao organismo. A ingestão contínua e desequilibrada de alimentos com alto teor de gorduras saturadas e gorduras hidrogenadas, substâncias químicas embutidas em determinados alimentos, ou ainda substâncias resultantes da combustão de carvão associados às gorduras provenientes das carnes expostas a esses processos, pode vir a desencadear um estágio inicial neoplásico. Por outro lado, uma dieta equilibrada, abundante em fibras, vitaminas e proteínas vêm favorecendo na prevenção ao câncer, podendo ainda auxiliar, juntamente ao tratamento clínico, o retrocesso ou estacionamento do estágio carcinogênico.

A alimentação nutricionalmente desequilibrada, diretamente não ocasiona neoplasias, porém a sua ingestão freqüente torna mais significante o teor de rico quando associada a outros fatores propulsores do câncer, sejam eles interno (herança genética) ou externos (tabagismo, radiação).

A dieta equilibrada pode oferecer os micronutrientes essenciais ao corpo. Dessa forma o indivíduo deve buscar variações em seu cardápio para que haja um mais completo aproveitamento nutricional dos alimentos, sem deixar o organismo vulnerável à patologias e trazendo ganho na qualidade de vida.

\section{Referências}

ARNOT,W. T. (1998). The Breast cancer Prevention Diet. São Paulo: Objetiva.

CAVE, W. T. (1996). Dietary omega 3 polyunsaturated fast and breast cancer. Nutrition, 12,1, p.39-42.

GENNARI, J., GENNARI, M., FELIPPE JR., J. (2001). O Agaricus sylvaticus aumenta o número de células natural Killer em pacientes com câncer. Medicina Complementar, 1, 7, p.42.

HAYES, W. A. \& WRIGHT, S. H. (1979). Edble mushrooms. (In: Rose, A. H. Economic microbiology: microbial biomass). London, Academic Press, 31-176 p.

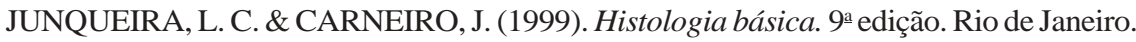
Guanabara Koogan.

LA VECCHIA \& C. TAVANI (1998). Fruit and vegetables, and human cancer. Eur. J. 
Cancer Prev. 7, p.3-8.

LEDERER, J. (1990). Alimentação e câncer. 3ㄹ edição. São Paulo: Editora Malone Dois.

LEWIN, B. (2001). Genes VII. Porto Alegre. Artmed. 875-906 p.

MORI, L. (2002). Mutação e Câncer. Ciência hoje, 180, 30, p.34-37.

RAJARATHAM, S. \& BANO, Z. (1987). Pleurotus mushroms. Part. IB. Pathology, in vitro and in vivo growth requirements, and world status. Cr. Ver. Rev. Food Sci. Nutr. 26, 3, p.243-311.

SGARBIERI, V.C. (1999). The role of dietary energy and of macrocomponents of foods in modulating carcinogenesis (an overview). Ciência e Cultura Journal of the Brazilian Association for the Advancement of Science, 51, 2, p.104-121.

TORTORA, G. J. \& GRABOWSKI, S. R. (2002). Princípios de Anatomia e Fisiologia Humana. $9^{a}$ edição. Rio de Janeiro: Guanabra Koogan.

Coordenação de Prevenção e Vigilância do INCA/MS-CONPREV (2000). URL:http:// www.inca.org.

Instituto Nacional do Câncer (2001). Registros de Câncer. URL:http://www.inca.org.

Núcleo de Apoio ao Paciente com Câncer - NAPACAN (2001). Manual do Paciente. URL:http://www.napacan.org.br 